\title{
-
}

\section{Leptin-Sensitive JAK2 Activation in the Regulation of Tau Phosphorylation in PC12 Cells}

\author{
Meixia Guo ${ }^{a}$ Dongliang Lia Huijun Shen ${ }^{a}$ Baijie Jin ${ }^{a}$ Yankai Ren ${ }^{a}$ Manli Lia \\ Ying Xing ${ }^{b}$ \\ aDepartment of Physiology, Sanquan Medical College, Xinxiang Medical University, Xinxiang, \\ ${ }^{b}$ Department of Physiology, University of Zhengzhou, Zhengzhou, China
}

\section{Key Words}

PC12 cells $\cdot$ JAK2 $\bullet$ Leptin $\bullet$ Tau $\bullet A \beta$

\begin{abstract}
Background/Aims: Alzheimer's disease (AD) is characterized by two major hallmarks: the deposition and accumulation of $\beta$-amyloid $(A \beta)$ peptide and hyperphosphorylated tau in intracellular neurofibrillary tangles. Sets of evidence show that leptin reduces $A \beta$ production and tau phosphorylation. Herein, we investigated the signaling pathways activated by leptin, to extensively understand its mechanism. Methods: Western blotting was employed to assess the protein abundance of p-tau and BAX, MTT assay to decipher the cells viability. Results: Leptin decreased tau phosphorylation, an effect was dependent on the activation of JAK2. Conclusion: The data suggest that JAK2 is involved in AD-related pathways.
\end{abstract}

\section{Introduction}

Alzheimer's disease (AD) is characterized by two major hallmarks: the deposition and accumulation of $\beta$-amyloid $(A \beta)$ peptide in extracellular plaques, the deposition of hyperphosphorylated tau in intracellular neurofibrillary tangles (NFTs) [1].

Leptin, an adipocytokine produced endogenously in the brain [2-5], is decreased in $\mathrm{AD}$ patients [6] and has also been shown to reduce $\mathrm{A} \beta$ levels in vitro and in vivo [7-9]. On bindig to the ObRb [10], leptin leads to the activation of several intracellular signaling pathways, including JAK/STATS pathway [11]. JAK/STAT signaling exerts diverse effects on a number of biological processes including immunity, hematopoiesis, inflammation and development [12]. Furthermore, it has been demonstrated that intraneuronal $A \beta$ causes memory impairment by attenuating JAK-STAT signaling in hippocampal neurons [1]. Sets of evidence show that leptin reduces $\beta$-amyloid $(A \beta)$ production and tau phosphorylation, 
Guo et al.: JAK2 Activation Against Tau Phosphorylation

and various reports demonstrate the interaction between leptin and JAK-STAT pathway $[13,14]$. However, there is still no evidence showing the related mechanism. Here, we have reported for the first time the leptin-sensitive JAK2/STAT5 activation in the regulation of tau phosphorylation and A $\beta$-induced apoptosis in PC12 cells.

In this study we have established an AD model from the adrenal pheochromocytoma PC12 cell line, and show that the hyperphosphorylation of tau protein and apoptosis induced by $\mathrm{A} \beta_{25-35}$ are abolished by JAK2, which is leptin sensitive.

\section{Materials and Methods}

\section{Cell culture}

Highly differentiated neuron-like PC12 cells(Shanghai Institutes for Biological Sciences, the Chinese Academy of Sciences, Shanghai, China) were cultured in DMEM medium supplemented with $10 \%$ FCS and $1 \%$ penicillin/streptomycin under standard conditions. Since $A \beta_{25-35}$ has the functional domain of $A \beta$ required for both neurotrophic and neurotoxic effects $[15,16]$, the PC12 Cells grown on the coverslips were treated in 30 $\mu \mathrm{M} \mathrm{A} \beta_{25-35}$ (Sigma Aldrich, USA) in the presence or absence of leptin(Sigma Aldrich,USA) and/or JAK2 inhibitor TG101348 (Axon Medchem, The Netherlands) for 24h.

\section{Western blotting}

Total protein was prepared. Cells were lysed in RIPA buffer (Beyotime, Shanghai, China) with $1 \%$ phenylmethylsulfonyl fluoride (Beyotime) and 1\% protein phosphatase inhibitor (Beyotime) on ice for $30 \mathrm{~min}$. The samples were centrifuged at $14,000 \mathrm{rpm}$ and $4^{\circ} \mathrm{C}$ for $20 \mathrm{~min}$. The supernatant was removed and used for Western blotting. Total protein $(40-60 \mu \mathrm{g})$ was separated by SDS-PAGE, thereafter transferred to PVDF membranes and blocked in 5\% non-fat milk/Tris-buffered saline/Tween-20 (TBST) at room temperature for 1 hour. Membranes were probed overnight at $4^{\circ} \mathrm{C}$ with polyclonal rabbit anti-p-tau(1:1000, cell signaling), $\mathrm{ObRb}(1: 1000$, cell signaling), and p-JAK2 (1:700, cell signaling). After incubation with horseradish peroxidaseconjugated anti-rabbit secondary antibody (1:2000, Sigma, United States) for $1 \mathrm{~h}$ at room temperature, the bands were visualized with enhanced chemiluminescence reagents (Sigma, United States). Membranes were also probed with ACTIN antibody as loading control. Densitometric analysis was performed using quantity One software (Abbiotec, United States).

\section{Cell viability assay}

PC12 cells were grown in DMEM medium supplemented with 10\% FCS and 1\% penicillin/streptomycin. The cells were incubated in a stable environment with $5 \% \mathrm{CO}_{2}$ at $37^{\circ} \mathrm{C}$ in a humidified incubator. The medium was replaced every 24 hours. Cells were grown to about $80 \%$ confluence prior to $\mathrm{A} \beta_{25-35}$ treatment, and then exposed to $\mathrm{A} \beta_{25-35}$ at $30 \mu \mathrm{M}$.

To measure the effects of leptin upon $A \beta_{25-35}$-induced apoptosis in PC12 cells, cells were treated with

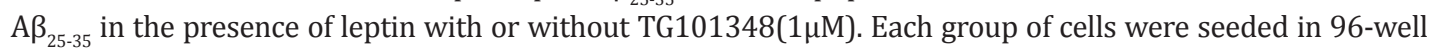
microtiter plates and incubated for 24 hours. At different points, $20 \mu$ of MTT was added to each well followed by 4 hours incubation.

The medium was discarded and $150 \mu \mathrm{l}$ of DMSO was added into each well, and incubated for $20 \mathrm{~min}$. The OD (optical density) $492 \mathrm{~nm}$ was measured. The proliferation inhibition rate was calculated as: (1-the OD of the experimental group/the OD of the control group) $\times 100 \%$. Each experiment was repeated three times.

\section{Quantification of mRNA expression}

Total RNA was extracted from PC12 cells in TriFast (Peqlab, United States) according to the manufacturer's instructions. After DNAse digestion reverse transcription of total RNA was performed using Transcriptor High Fidelity cDNA Synthesis Kit (Roche Diagnostics, Shanghai). Real-time polymerase chain reaction (RT-PCR) of the respective genes were set up in a total volume of $20 \mu \mathrm{l}$ using $40 \mathrm{ng}$ of cDNA, $500 \mathrm{nM}$ forward and reverse primer and 2x GoTaq ${ }^{\circledR}$ qPCR Master Mix (Promega, United States) according to the manufacturer's protocol. Cycling conditions were as follows: initial denaturation at $95^{\circ} \mathrm{C}$ for $2 \mathrm{~min}$, followed by 40 cycles of $95^{\circ} \mathrm{C}$ for 15 sec, $58^{\circ} \mathrm{C}$ for $15 \mathrm{sec}$ and $68^{\circ} \mathrm{C}$ for $20 \mathrm{sec}$. For amplification the following primers were used ( $5^{\circ}>3^{\prime}$ orientation): 
The following primers were used:

Human Tbp (TATA box-binding protein):

forward ( $\left.5^{\prime}-3^{\prime}\right)$ : ACTCCTGCCACACCAGCC

reverse (5'-3'): GGTCAAGTTTACAGCCAAGATTCA

Human Bax

forward (5'-3'): ATGTGAAGCACCCTTTCCTG

reverse (5'-3'): TAGAACAGCTCTCCGCCATT

Specificity of PCR products was confirmed by analysis of a melting curve. Real-time PCR amplifications were performed on a CFX96 Real-Time System (Bio-Rad, United States) and all experiments were done in duplicate. The house-keeping gene Tbp (TATA binding protein) was amplified to standardize the amount of sample RNA. Relative quantification of gene expression was achieved using the $\Delta$ CT method as described [17].

\section{Statistics}

Data are provided as means \pm SEM, $n$ represents the number of independent experiments. All data were tested for significance using unpaired Student t-test or ANOVA. Only results with $\mathrm{p}<0.05$ were considered statistically significant.

\section{Results}

In order to identify the effect of leptin upon the $A \beta_{25-35}$-induced cytotoxicity in PC12 cells, cells were pretreated with $\mathrm{A} \beta_{25-35}$ in $30 \mu \mathrm{M}$ prior to MTT assay. As illustrated in Fig. 1, exposure of cells to $A \beta_{25-35}$ for 24 hours leaded to a decrease of the cell viability, an effect abolished by leptin $(125 \mathrm{ng} / \mathrm{ml})$ treatment.

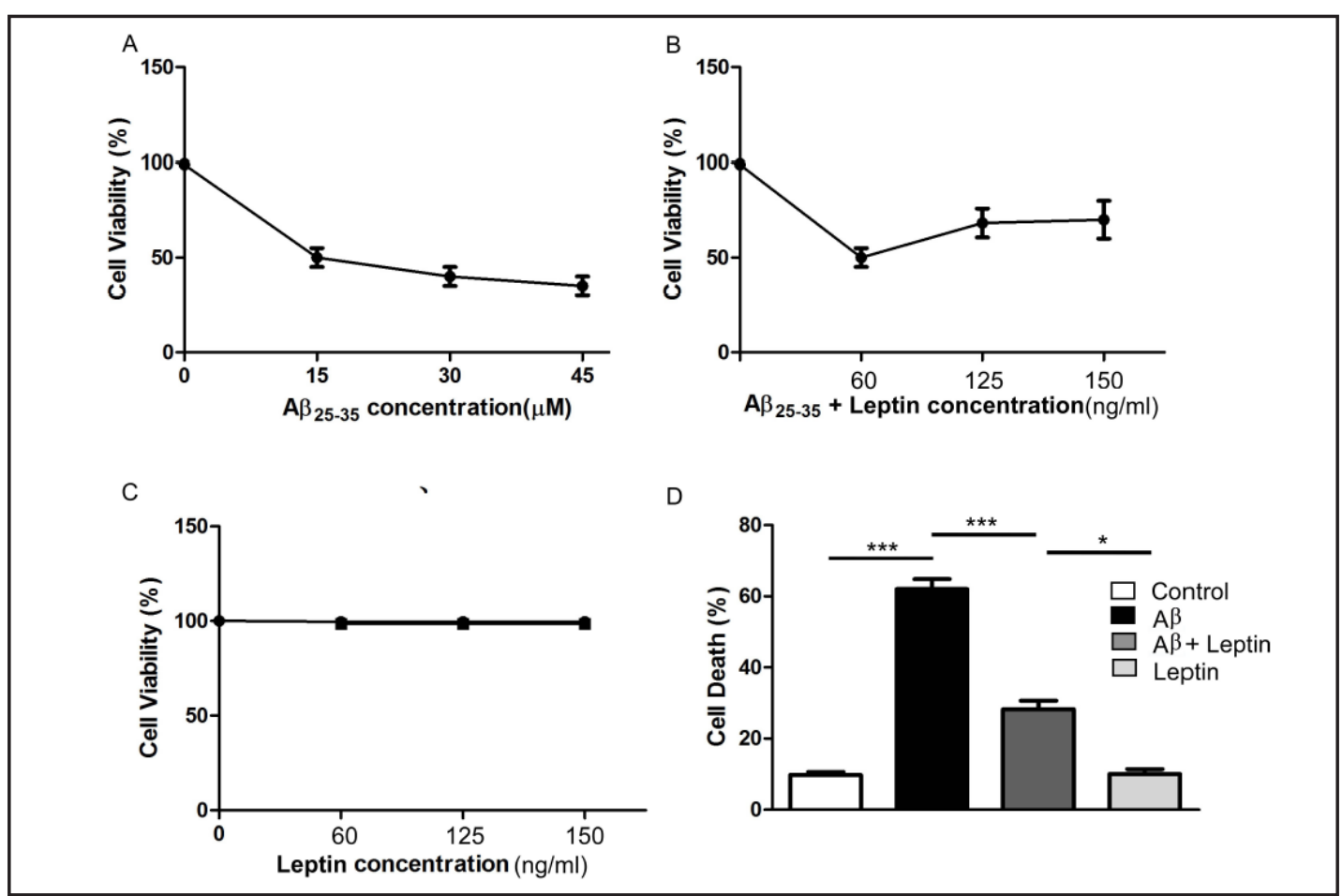

Fig. 1. Effect of Leptin on $A \beta_{25-35}$-induced neurotoxicity in PC12 cells. A: PC12 cells were treated with different concentrations of $A \beta_{25-35}$ for 24h. B: PC12 cells were incubated with different concentrations of Leptin $(4 \mathrm{nM})$ in the presence of $A \beta_{25-35}(30 \mu \mathrm{M})$ for $24 \mathrm{~h}$. C: PC12 cells were incubated with different concentrations of Leptin $(4 \mathrm{nM})$ in the absence of $A \beta_{25-35}(30 \mu \mathrm{M})$ for $24 \mathrm{~h}$. D: MTT analyse was used to determine cell death. PC12 cells were incubated with $A \beta_{25-35}(30 \mu \mathrm{M})$ without or with the treatment of Leptin $(125 \mathrm{ng} / \mathrm{ml})$ for $24 \mathrm{~h}$. Data are means \pm SEM $\left(n=5\right.$ independent experiments). ${ }^{* * *}(\mathrm{p}<0.001)$ indicate statistically significant difference. 
Fig. 2. Effect of leptin on OBR band JAK2 phosphorylation. A: Original western blot showing the protein abundance of OBRb, p-JAK2 and JAK2 as well as respective actin in PC12 cells with Leptin(125 ng/ml) treatment. B: Arithmetic means \pm SEM ( $\mathrm{n}=4$ independent experiments) of OBRb in PC12 cells without(white bar) or with Leptin(125 ng/ml)(black bar) treatment. C: Arithmetic means \pm SEM ( $n=4$ independent experiments) of p-JAK2 in PC12 cells without(white bar) or with Leptin(125 ng/ml)(black bar)treatment. ${ }^{* * *}(\mathrm{p}<0.001)$ indicate statistically significant difference.

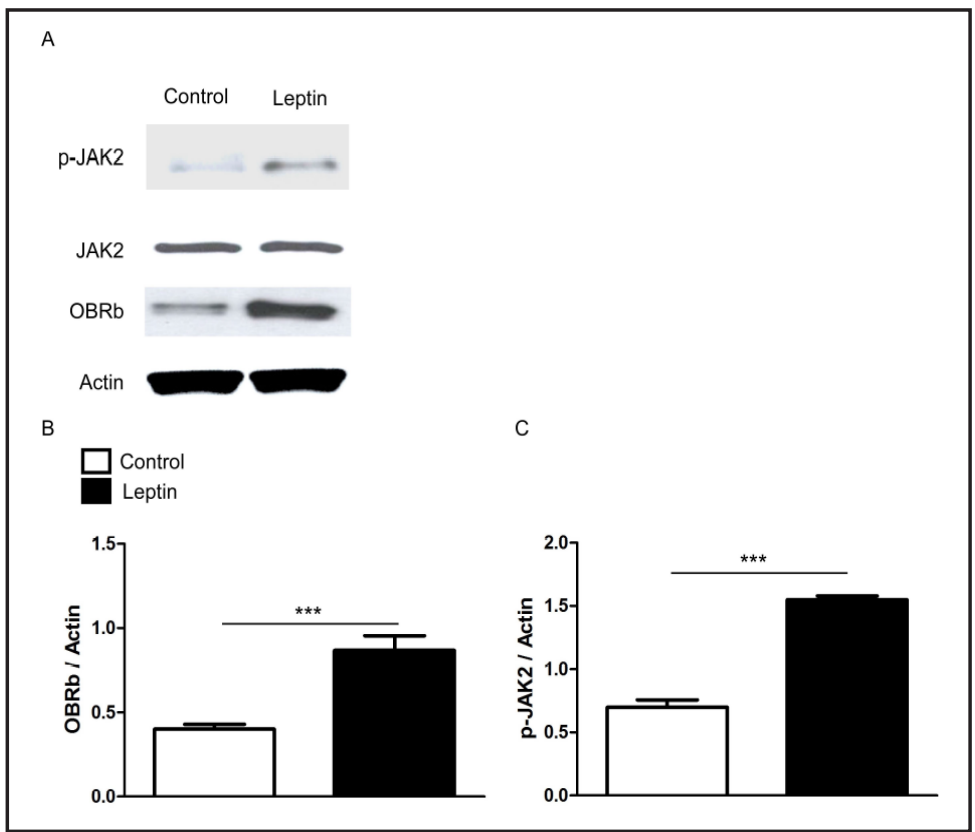

Fig. 3. Inhibition of JAK2 kinase blocked tau phosphorylation in PC12 cells. A: Original western blot showing the protein abundance of p-tau and tau protein as well as respective actin in $\mathrm{A} \beta_{25-35}$-pretreated PC12 cells without or with Leptin (125 ng/ml) in the presence or absence of TG101348 (1 $\mu \mathrm{M})$. B: Arithmetic means \pm SEM ( $n=3$ independent experiments) of p-tau in in $A \beta_{25-35}$-pretreated PC12 cells without(black bar) or with Leptin(125 ng/ml) in the presence(light grey) or absence(dark grey) of TG101348. ${ }^{* *}(\mathrm{p}<0.01),{ }^{* * *}(\mathrm{p}<0.001)$ indicate statistically significant difference.

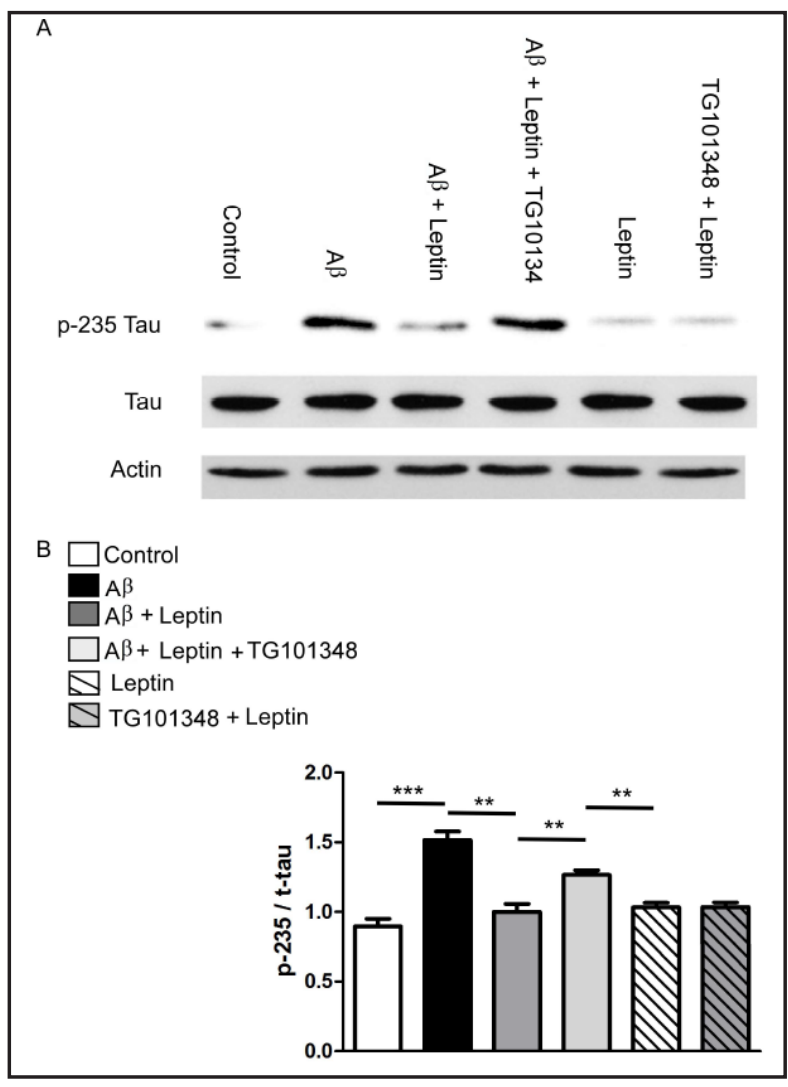

In order to confirm the expression of $\mathrm{ObRb}$ and the effect of leptin upon JAK2 activation, cells were treated without or with leptin $(125 \mathrm{ng} / \mathrm{ml})$ and performed western blotting. As illustrated in Fig. 2, leptin receptor ObRb was expressed in PC12 cells and leptin enhanced the protein abundance of $\mathrm{ObRb}$ and $\mathrm{p}-\mathrm{JAK} 2$.

In orderto explore whether the effectofleptin on $\mathrm{A} \beta_{25-35}$-mediated tauhyperphosphorylation is sensitive to the JAK2, $A \beta_{25-35}$-pretreated PC12 cells were treated with leptin $(125 \mathrm{ng} / \mathrm{ml})$ with or without TG101348(1 $\mu \mathrm{m})$. As illustrated in Fig. 3, treatment with TG101348(1 $\mu \mathrm{m})$ 
Fig. 4. Inhibition of JAK2 kinase blocked mRNA level of Bax in PC12 cells. Arithmetic means \pm SEM ( $\mathrm{n}=4$ independent experiments) of BAX in $\mathrm{A} \beta_{25-35}$-pretreated PC12 cells without(black bar) or with Leptin in the presence(light grey) or absence(dark grey) of TG101348. ${ }^{* *}(\mathrm{p}<0.01)$, $* * *(\mathrm{p}<0.001)$ indicate statistically significant difference.

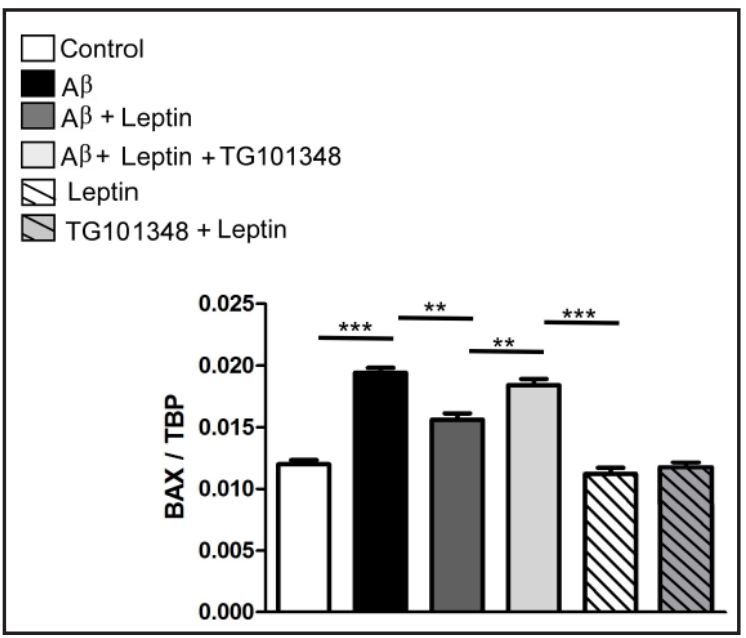

Fig. 5. GSK-3 protein abundance in $A \beta_{25-35}$-pretreated PC12 cells. A: Original western blot showing the protein abundance of GSK-3 and respective actin in $A \beta_{25-35}$-pretreated PC12 cells with Leptin treatment $(125 \mathrm{ng} / \mathrm{ml})$ in the presence or absence of TG101348(1 $\mu \mathrm{M})$. B: Arithmetic means \pm SEM ( $n=4$ independent experiments) of GSK-3 and respective actin protein abundance without(white bar) and with Leptin treatment(125ng/ml)(dark bar) in the presence of TG101348(1 $1 \mu \mathrm{M})$ (grey bar) in $\mathrm{A} \beta_{25-35}$-pretreated PC12 cells. ${ }^{* * *}(\mathrm{p}<0.001)$ indicate statistically significant difference.

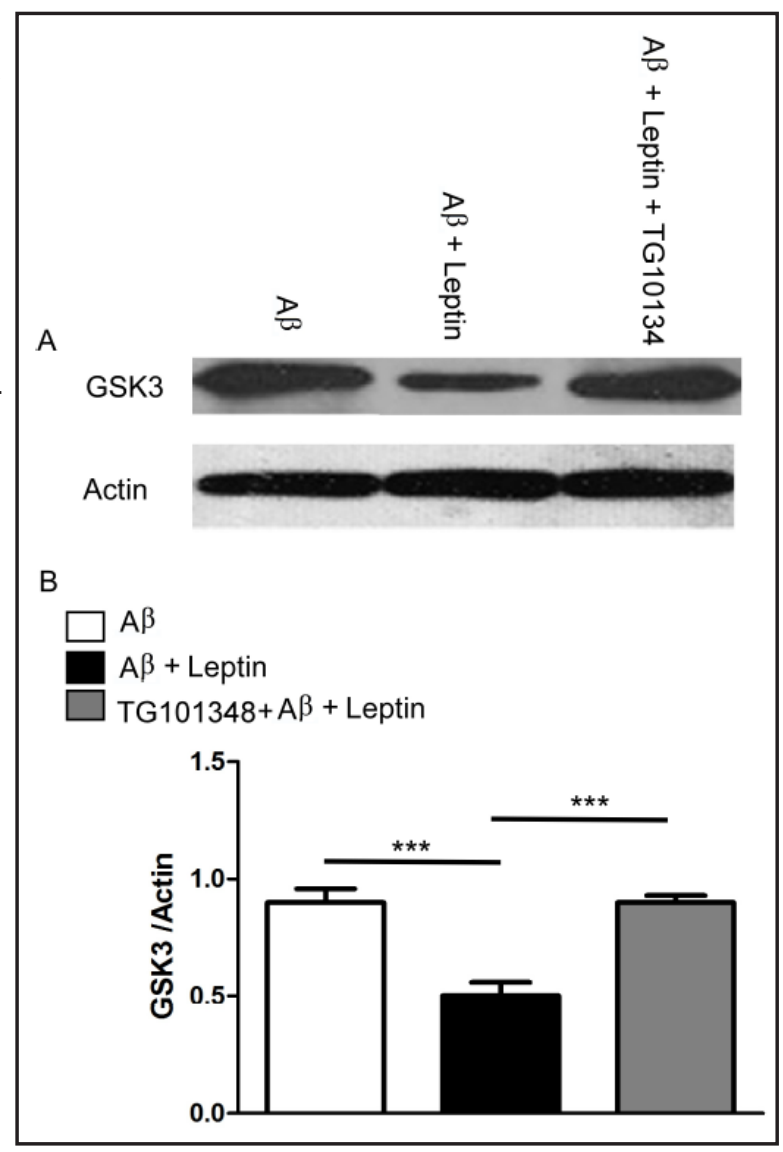

significantly blunted Leptin-mediated inhibition of $A \beta_{25-35}$ phosphorylation of Tau at Ser252 (Fig. 3).

In order to elucidate the role of leptin in the apoptosis-related gene expression and whether the effect is JAK2 dependent, RT-PCR was applied to detect the transcriptional level of Bax in PC12 cells. As shown in Fig. 4, treatment with TG101348(1 $\mu \mathrm{m})$ significantly blunted Leptin-mediated inhibition of $A \beta_{25-35}$ upon the mRNA level of Bax.

In order to explore the effect of leptin on GSK3 and whether the effect is sensitive to JAK2 pathway. A $\beta_{25-35}$-pretreated PC12 cells were treated with leptin and/or TG101348. As illustrated in Fig. 5, treatment with TG101348 $(1 \mu \mathrm{m})$ significantly blunted Leptin-mediated inhibition of GSK3 protein abundance in $A \beta_{25-35}$-pretreated PC12 cells. 


\section{SiGínAis}

Neurosignals 2016;24:88-94

\begin{tabular}{l|l}
\hline DOI: $10.1159 / 000442615$ & (c) 2016 The Author(s). Published by S. Karger AG, Basel
\end{tabular}

Published online: September 08, 2016 www.karger.com/nsg

Guo et al.: JAK2 Activation Against Tau Phosphorylation

\section{Discussion}

This study was conceived to assess the role of leptin signaling in the modulation of AD. We demonstrate that $A \beta_{25-35}$ induces a marked upregulation of tau phosphorylation and apoptosis, the effects of which are reversed by treatment with the adipocytokine leptin. Leptin is known to activate JAK [18] and our present experiments indicate that JAK2/STAT5 mediates leptin's effects.

JAK/STAT pathway is a common mediator of astrocyte reactivity, which is a hallmark of neurodegenerative diseases [19].GSK-3 is highly expressed in the brain of AD patient [20], which results in the over-phosphorylation of Tau and the formation of NTF [21]. Reports show that leptin inhibits GSK-3 $\beta$ to prevent tau phosphorylation in neuronal cells $[22,23]$. Furthermore, GSK-3 $\beta$ is downstream of JAK2 in H9C2 cells [24]. Here we have demonstrated that leptin inhibits GSK-3 $\beta$ to prevent tau phosphorylation by activating JAK2 in PC1 2 cells.

Our findings have shown that Leptin modulates $A \beta$ production through JAK2 pathway. $\mathrm{A} \beta$ has been reported to induce neuronal tauopathy in APP-V717I×Tau-P301L biogenic mice through activation of GSK-3 $\beta$ [25]. Therefore, in addition to directly inactivating GSK-3 $\beta$ by kinases, the Leptin-JAK pathway may also indirectly inactivate the enzyme via regulating A $\beta$.

It was reported previously that leptin treatment could protect cells in the developing rodent brain against apoptosis. We found that leptin blunted the effects of $A \beta_{25-35}$ upon cell viability. These findings suggest that leptin exerts a cytoprotective role in $\mathrm{AD}$.

Presently, we have demonstrated that leptin regulates the major AD pathways via distinct JAK2-dependent mechanisms in neuronal cells. Taken together, Leptin, potentially JAK2 activators, provides a novel therapeutic approach to AD treatment.

\section{Disclosure Statement}

All authors disclose that they have not any potential conflict of interest (e.g., consultancies, stock ownership, equity interests, patent-licensing arrangements, lack of access to data, or lack of control of the decision to publish).

\section{References}

1 Chiba T, Yamada M, Sasabe J, Terashita K, Shimoda M, Matsuoka M, Aiso S: Amyloid-beta causes memory impairment by disturbing the JAK2/STAT3 axis in hippocampal neurons. Mol Psychiatry 2009;14:206-222.

2 Li HY, Wang LL, Yeh RS: Leptin immunoreactivity in the central nervous system in normal and diabetic rats. Neuroreport 1999;10:437-442.

3 Ur E, Wilkinson DA, Morash BA, Wilkinson M: Leptin immunoreactivity is localized to neurons in rat brain. Neuroendocrinology 2002;75:264-272.

4 Marwarha G, Dasari B, Prasanthi JRP, Schommer J, Ghribi O: Leptin reduces the accumulation of Abeta and phosphorylated tau induced by 27-hydroxycholesterol in rabbit organotypic slices. J Alzheimers Dis 2010;19:1007-1019.

5 Greco SJ, Sarkar S, Johnston JM, Tezapsidis N: Leptin regulates tau phosphorylation and amyloid through AMPK in neuronal cells. Biochem Biophys Res Commun 2009 Feb 27;380:98-104.

6 Power DA, Noel J, Collins R, O'Neill D: Circulating leptin levels and weight loss in Alzheimer's disease patients. Dement Geriatr Cogn Disord 2001;12:167-170.

7 Tezapsidis N, Johnston JM, Smith MA, Ashford JW, Casadesus G, Robakis NK, Wolozin B, Perry G, Zhu XW, Greco SJ, Sarkar S: Leptin: a novel therapeutic strategy for Alzheimer's disease. J Alzheimers Dis 2009;16:731-740.

8 Ishii M: The Role of the Adipocyte Hormone Leptin in Alzheimer's Disease. Keio J Med 2016;65:21-21.

9 Magalhães CA, Carvalho MG, Sousa LP, Caramelli P, Gomes KB: Leptin in Alzheimer's disease. Clin Chim Acta 2015;450:162-168. 
10 Morton GJ, Schwartz MW: Leptin and the central nervous system control of glucose metabolism. Physiol Rev 2011;91:389-411.

11 Chen Y, Wu R, Chen H-Z, Xiao Q, Wang W-J, He J-P, Li X-X, Yu X-W, Li L, Wang P, Wan X-C, Tian X-H, Li S-J, Yu X, Wu Q: Enhancement of hypothalamic STAT3 acetylation by nuclear receptor Nur77 dictates leptin sensitivity. Diabetes 2015;64:2069-2081.

12 Levy DE, Darnell JE: Stats: transcriptional control and biological impact. Nat Rev Mol Cell Biol 2002;3:651-662.

13 Li X-M, Yan H-J, Guo Y-S, Wang D: The role of leptin in central nervous system diseases. Neuroreport 2016;27:350-355.

14 Wu K, Tan X-Y, Xu Y-H, Chen Q-L, Pan Y-X: JAK and STAT members of yellow catfish Pelteobagrus fulvidraco and their roles in leptin affecting lipid metabolism. Gen Comp Endocrinol 2016;226:14-26.

15 Yankner BA, Duffy LK, Kirschner DA: Neurotrophic and neurotoxic effects of amyloid beta protein: reversal by tachykinin neuropeptides. Science 1990;250:279-282.

16 Ashenafi S, Fuente A, Criado JM, Riolobos AS, Heredia M, Yajeya J: Beta-Amyloid peptide25-35 depresses excitatory synaptic transmission in the rat basolateral amygdala "in vitro". Neurobiol Aging 2005;26:419-428.

17 Matsuzaki T, Iwasa T, Tungalagsuvd A, Munkhzaya M, Kawami T, Yamasaki M, Murakami M, Kato T, Kuwahara A, Yasui T, Irahara M: The responses of hypothalamic NPY and OBRb mRNA expression to food deprivation develop during the neonatal-prepubertal period and exhibit gender differences in rats. Int J Dev Neurosci 2015;41:63-67.

18 Wang Y-N, Yang M, Yu L-H, Guo J, Chen N, He L: [Leptin play the key role in astroglial differentiation of mouse neural stem cells and regulated the STAT3 signaling through Jak-STAT3 pathway]. Sichuan Da Xue Xue Bao Yi Xue Ban 2014;45:552-6- 562.

19 Ben Haim L, Ceyzériat K, Carrillo-de Sauvage MA, Aubry F, Auregan G, Guillermier M, Ruiz M, Petit F, Houitte D, Faivre E, Vandesquille M, Aron-badin R, Dhenain M, Déglon N, Hantraye P, Brouillet E, Bonvento G, Escartin C: The JAK/STAT3 pathway is a common inducer of astrocyte reactivity in Alzheimer"s and Huntington"s diseases. J Neurosci 2015;35:2817-2829.

20 Asuni AA, Hooper C, Reynolds CH, Lovestone S, Anderton BH, Killick R: GSK3alpha exhibits beta-catenin and tau directed kinase activities that are modulated by Wnt. Eur J Neurosci 2006;24:3387-3392.

21 Caccamo A, Maldonado MA, Majumder S, Medina DX, Holbein W, Magrí A, Oddo S: Naturally secreted amyloidbeta increases mammalian target of rapamycin (mTOR) activity via a PRAS40-mediated mechanism. J Biol Chem 2011;286:8924-8932.

22 Greco SJ, Sarkar S, Casadesus G, Zhu X, Smith MA, Ashford JW, Johnston JM, Tezapsidis N: Leptin inhibits glycogen synthase kinase-3beta to prevent tau phosphorylation in neuronal cells. Neurosci Lett 2009;455:191194.

23 Greco SJ, Sarkar S, Johnston JM, Zhu X, Su B, Casadesus G, Ashford JW, Smith MA, Tezapsidis N: Leptin reduces Alzheimer's disease-related tau phosphorylation in neuronal cells. Biochem Biophys Res Commun 2008;376:536-541.

24 Gross ER, Hsu AK, Gross GJ: The JAK/STAT pathway is essential for opioid-induced cardioprotection: JAK2 as a mediator of STAT3, Akt, and GSK-3 beta. Am J Physiol Heart Circ Physiol 2006;291:H827-34.

25 Terwel D, Muyllaert D, Dewachter I, Borghgraef P, Croes S, Devijver H, Van Leuven F: Amyloid activates GSK3beta to aggravate neuronal tauopathy in bigenic mice. Am J Pathol 2008;172:786-798. 